
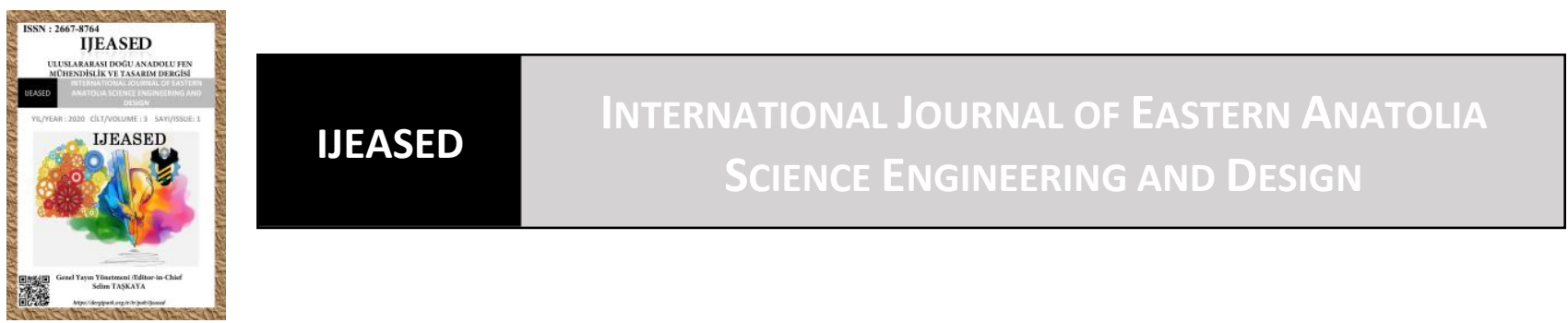

\author{
Uluslararası Doğu Anadolu Fen Mühendislik ve Tasarım Dergisi \\ ISSN: 2667-8764, 3(1), 55-71, 2021 \\ https://dergipark.org.tr/tr/pub/ijeased
}

Araştırma Makalesi / Research Article

Doi: $10.47898 /$ ijeased.828639

\title{
Uzun Süreli Yaşlandırılmış Etilen Vinil Asetat (EVA) Polimer Katkılı Asfalt Bağlayıcının Yorulma Ömrünün İncelenmesi
}

\author{
Sajjad HASSANPOUR KASANAGH ${ }^{1 *}$, Perviz AHMEDZADE ${ }^{1}$, Taylan GÜNAY ${ }^{1}$
}

${ }^{1}$ Ege Üniversitesi, Mühendislik Fakültesi, İnşaat Mühendisliği Bölümü, İzmir, 35100, Türkiye.

\begin{tabular}{|c|c|c|}
\hline Yazar Kimliği / Author ID (ORCID Number) & \multicolumn{2}{|c|}{ Makale Süreci / Article Process } \\
\hline Sorumlu Yazar / Corresponding author : & Geliş Tarihi / Received Date : & 20.11 .2020 \\
\hline sajjad.hassanpour.kasanagh@mail.ege.edu.tr & Revizyon Tarihi / Revision Date : & 15.12 .2020 \\
\hline (iD https://orcid.org/0000-0001-9484-4324, S.H. Kasanagh & Kabul Tarihi / Accepted Date : & 02.01 .2021 \\
\hline (iD) https://orcid.org/0000-0001-8348-5901 , P. Ahmedzade & Yayım Tarihi / Published Date & 15.07.2021 \\
\hline (iD https://orcid.org/0000-0002-2669-6320 , T. Günay & & \\
\hline
\end{tabular}

Alıntı / Cite : Hassanpour Kasanagh, S., Ahmedzade, P., Günay, T. (2021). Uzun Süreli Yaşlandırılmış Etilen Vinil Asetat (EVA) Polimer Katkılı Asfalt Bağlayıcının Yorulma Ömrünün İncelenmesi, Uluslararası Doğu Anadolu Fen Mühendislik ve Tasarım Dergisi, 3(1), 55-71.

\section{Özet}

$\mathrm{Bu}$ çalışmada, polimer katkılı B50/70 sınıfına ait bitümlü bağlayıcının laboratuvar ortamında uzun süreli yaşlandırılması gerçekleştirilerek asfalt kaplamadaki yorulma ömrü tahmin edilmiştir. Bitümlü sıcak karışımların (BSK) orta sıcaklıklardaki yorulma performansını arttırma amacıyla Etilen Vinil Asetat (EVA) polimer katkısı bitüme yaygın olarak eklenmektedir. Asfalt bağlayıcıların modifiye işlemi tamamlanmasının ardından numuneler sırasıyla dönel ince film etüvü (RTFO) deneyiyle kısa süreli ve basınçlı yaşlandırma kabı (PAV) deneyiyle uzun süre yaşlandırmaya maruz bırakılmıştır. Yorulma performansının belirlenmesi Anton Paar Smart Pave Plus 301 DSR cihazıyla gerçekleştirilmiştir. Çalışmada, yorulma parametresi, Superpave yorulma deneyi ve lineer farklı genlik (LAS) deneyleriyle incelenmiş ve bu iki farklı deneyden elde edilen veriler karşılaştırılmıştır. Çalışma sonucunda, EVA katkısının saf asfalt bağlayıcının yorulma performansını ve yorulma ömrünü önemli ölçüde arttırdığı tespit edilmiştir.

Anahtar Kelimeler: Asfalt Bağlayıcı, Polimer, Superpave Yorulma Parametresi, DSR, Lineer Farklı Genlik (LAS). 


\title{
An Investigation on Fatigue Life of Long Term Aged Ethylene-Vinyl Acetate (EVA) Polymer Modified Asphalt Binder
}

\begin{abstract}
The fatigue life of polymer modified B50/70 asphalt binder obtained from Turkey refinery was studied in this work. EVA modifier is used extensively to improve the fatigue performance of binder in the middle temperature range. After the EVA modification, the binders were exposed to short term and long term aging processes by means of rolling thin film oven (RTFO) and pressure aging vessel (PAV) tests, respectively. The fatigue performance of binders was evaluated by dynamic shear rheometer (DSR) Anton Paar Smart Pave Plus 301. The fatigue parameter was investigated by means of two different tests namely Superpave fatigue test and linear amplitude sweep (LAS) test, and the results obtained from these two tests were compared. The results showed that EVA modifier extends the fatigue performance and the fatigue life of binders.
\end{abstract}

Keywords: Asphalt Binder, Polymer, Superpave Fatigue Parameter, DSR, Linear Amplitude Sweep (LAS).

\section{Giriş}

Asfalt bağlayıcıların yorulma performansının belirlenmesinde uzun süreli yaşlandırılmış bağlayıcıların yorulma deneylerine tabi tutulması istenmektedir. Böylece asfalt bağlayıcının karışım içerisindeki yorulma ömrü 5-8 yıl trafik hizmeti sonucu ortaya çıkmaktadır. Bunun için, bağlayıcı ilk önce kısa süreli yaşlanma işlemini temsil eden dönel ince film etüvü (RTFO) deneyine tabi tutulmaktadır. Böylelikle BSK'nın karıştırma ve uygulama sırasındaki oksidasyon ve buharlaşma sonucu oluşacak kısa süreli yaşlanma laboratuvar ortamında simüle edilmektedir. Bunun ardından, hizmetteki uzun süreli yaşlanması basınçlı yaşlandırma kabı (PAV) deneyiyle simüle edilmelidir (Sadeghian ve ark., 2019).

Asfalt kaplamalarda tekerlek izi, yorulma çatlağı ve termal çatlakları karayolu hizmet ömrünü azaltan en yaygın bozulmalar olarak tanımlanmıştır (Ashish ve ark., 2017; Behnood ve Gharehveran, 2019; Nasr ve Pakshir, 2019; Saboo ve Kumar, 2015). Asfalt bağlayıcının asfalt kaplamadaki performansı modifikasyon yöntemleriyle arttırılmaktadır. Katkı malzemesi kullanımındaki amaç, bitümlü sıcak karışımların (BSK) özelliklerinin iyileştirilmesi ve bu suretle oluşacak olan bozulmaların ortadan kaldırması veya geciktirilmesidir (Kalantar ve ark., 2012).

Yorulma çatlağı, trafik yükü ve çevresel faktörlerden kaynaklı tekrarlı gerilmeler sonucunda oluşan ve kaplama yüzeyinde timsah sırtı çatlaması şeklinde görülen esnek kaplamalardaki en belirgin bozulma türlerinden biridir (Ameri ve ark., 2018; Kataware ve Singh, 2018; Ziari ve ark., 2014). Superpave yorulma parametresi $\left(\mathrm{G}^{*} \times \sin \delta\right)$ asfalt kaplaması kullanılacak olan bağlayıcının yorulmaya karşı performansını tahmin etme amacıyla SHRP programı kapsamında geliştirilmiştir (Sabouri ve ark., 2018). Buna ek olarak, Wisconsin Üniversitesi araştırmacıları asfalt bağlayıcının 
yorulma çatlama direncini değerlendirmesi için tekerrür halinde artsal gerilmelere maruz bırakarak bitümün daha kısa zamanda hasar görmesini sağlayarak lineer farklı genlik (LAS) deney yöntemini geliştirmişlerdir (Bahia ve ark., 2013). LAS deneyi sonucunda bitümün yorulma ömrü (yorulma bozulmasına uğrayan döngü (trafik) sayısı) viskoelastik sürekli hasar (VECD) formülasyonu yardımıyla tahmin edilmektedir.

Bunu yanı sıra, polimer katkıları ile modifiye edilmiş bağlayıcıların hangi rafineri kaynaklardan üretildiği kimyasal içeriklerinin değişiklik göstermesi nedeniyle bitümün BSK'daki davranışını etkileyerek yorulma ömrünü tahmin etmesinde farklılık sağlamaktadır. VCED teorisi yöntemiyle Türkiye kaynaklı bitümlerin yorulma hasarı ve yorulma ömrü tahmini ilk defa Ege Üniversitesi araştırmacıları tarafından çeşitli polimer modifiyeli bağlayıcılar üzerinde incelenmiştir. Çalışmada, sitren-butadien-sitren (SBS), lastik tozu (GTR), polietilen gibi katkıların bitümün yorulma hasarını düşürdüğü ve yorulma ömrünü arttırdığını öne sürmüştür (Hassanpour-Kasanagh ve ark., 2020).

Etilen-vinil asetat (EVA) polimer malzemesi SBS gibi asfalt bağlayıcı modifikasyonu için yaygın şekilde kullanılmaktadır. EVA katkısının Türkiye kaynaklı bitümlerin performansının arttırması yönünde farklı çalışmalar bulunsa dahi son zamanlarda geliştirilmiş LAS deneyiyle incelenmesi ve VECD teorisi hesaplamalarıla bitümün yorulma hasarı ve yorulma ömrü tahmini üzerinde yeni araştırmaların yapılmasına ihtiyaç duyulmaktadır (Sengoz ve Isikyakar, 2008).

Mevcut çalışmanın amacı, EVA polimer modifiyeli TÜPRAŞ A.Ş. kaynaklı B50/70 bitümün Superpave yorulma $\left(\mathrm{G}^{*} \times \sin \delta\right)$ parametresi ve viskoelastik sürekli hasar (VECD) yöntemleriyle uzun süreli yaşlandırmasının gerçekleştirilmesi ve bu şekilde bağlayıcıların farklı gerilmelerde yorulma hasarı ve hizmet ömrünün kapsamlı şekilde tahmin edilmesidir.

\section{Malzemeler ve Metot}

\subsection{Malzemeler}

Çalışmada Türkiye'nin TÜPRAŞ A.Ş. rafinerisinden elde edilen 50/70 penetrasyon sınıfına sahip bitüm bağlayıcı malzeme olarak kullanılmaktadır. Bitümün fiziksel özellikleri Tablo 1'de verilmiştir. Modifikasyon için kullanılan polimer katkı DuPont firması tarafından üretilen Elvax ${ }^{\circledR} 420$, ağırlıç̧a \%18 vinil asetat komonomer içeriğine sahip bir etilen vinil asetat (EVA) kopolimerdir. Şeffaf renkli ve granül şeklinde olan katkının yumuşama noktası $53{ }^{\circ} \mathrm{C}$ 'dir. ISO 1183 standardına göre özgül ağırlığı 0,94'tür. EVA katkısının görünümü Şekil 1'de verilmiştir. 
Tablo 1. Çalışmada kullanılan bitümün fiziksel özellikleri.

\begin{tabular}{ccccc}
\hline Özellikler & Özgül Ağırlık & $\begin{array}{c}\text { Penetrasyon } \\
(\mathrm{dmm})\end{array}$ & $\begin{array}{c}\text { Yumuşama Noktası } \\
\left({ }^{\circ} \mathrm{C}\right)\end{array}$ & $\begin{array}{c}\text { Viskozite, } \\
135^{\circ} \mathrm{C}(\mathrm{cP})\end{array}$ \\
\hline B 50/70 & 1.027 & 52 & 43 & 398 \\
\hline
\end{tabular}

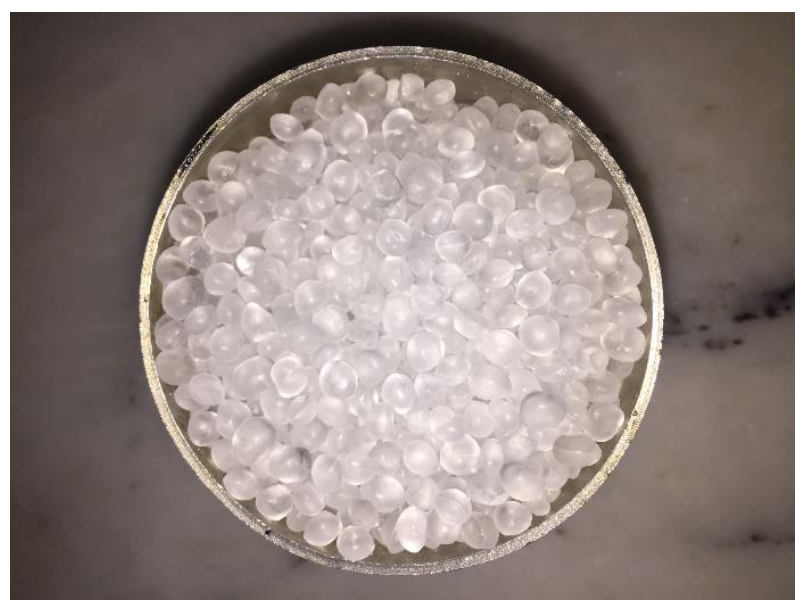

Şekil 1. Etilen vinil asetat (EVA) polimer katkıs1

\subsubsection{Modifikasyon İşlemi}

EVA polimer katk1 malzemesi ağırlıkça \%3-\%7 oranlarında saf bitüme eklenmiştir. B50/70 penetrasyonlu bitüm ilk önce akıcı hale gelinceye kadar etüvde 1sıtılmıştır. Katkı maddesi bitüme önceden belirlenmiş yüzdelerde $180^{\circ} \mathrm{C}$ sıcaklıkta ve 1000 devir/dak hızda aralıklarla (10 dk boyunca) eklenmiştir. Bu işlemin ardından polimer katkısının bitüm içerisinde iyice erimesi ve polimerik ağ oluşturması için karıştırıcı hızı 3000 devir/dak’ya yükseltilerek 60 dk boyunda karıştırma işlemi gerçekleşmiştir. Modifikasyon işlemi Silverson LSM markalı yüksek devirli mikser cihazı ile yapılmıştır. Hazırlanan numuneler kısa süre ve uzun süre yaşlandırma deneylerine tabi tutulması için kapalı şekilde depolanmıştır.

\subsubsection{Bağlayıcıların Kısa Süreli Yaşlandırılması}

BSK'ların inşaat tesisindeki karıştırma ve uygulama süresince meydana gelen ve kısa vadeli yaşlandırma olarak ifade edilen yaşlanması dönel ince film etüvü (RTFO) deneyiyle laboratuvar ortamında simüle edilmiştir. Deney ASTM D2872 şartnamesi çerçevesinde uygulanmıştır (ASTM D2872, 2012). Deney standarda uygun olarak RTFO cihazına yerleştirilen 8 adet şişesi ile yapılmıştır. Şişelerin her birine $35 \pm 0,5$ gram asfalt bağlayıcı numunesi doldurularak şişeler $163^{\circ} \mathrm{C}$ 'ye ayarlanan cihaza yerleştiriliştir. Numuneler dönen tabla üzerine yerleştirildikten sonra 
cihazın sıcaklığı tekrar $163^{\circ} \mathrm{C}^{\prime}$ ye ulaşıncaya kadar bekletirmiştir. Bunun ardından, tabla dakikada 15 devir yapacak şekilde ve 85 dakika süresince döndürülmüştür. Dönme esnasında asfalt bağlayıcılara cihazın içinde bulunan bir hava üfleyicisi aracılığıyla numunelere basınç akışı $4000 \pm 200 \mathrm{ml} /$ dakika seviyesinde olacak şekilde hava püskürtülmüş ve bu sayede bağlayıcıların hem sıcaklık ve hem hava etkisiyle kısa süreli yaşlandırılması gerçekleştirilmiştir. RTFO cihazının iç ve dış görünümü Şekil 2’de verilmiştir.

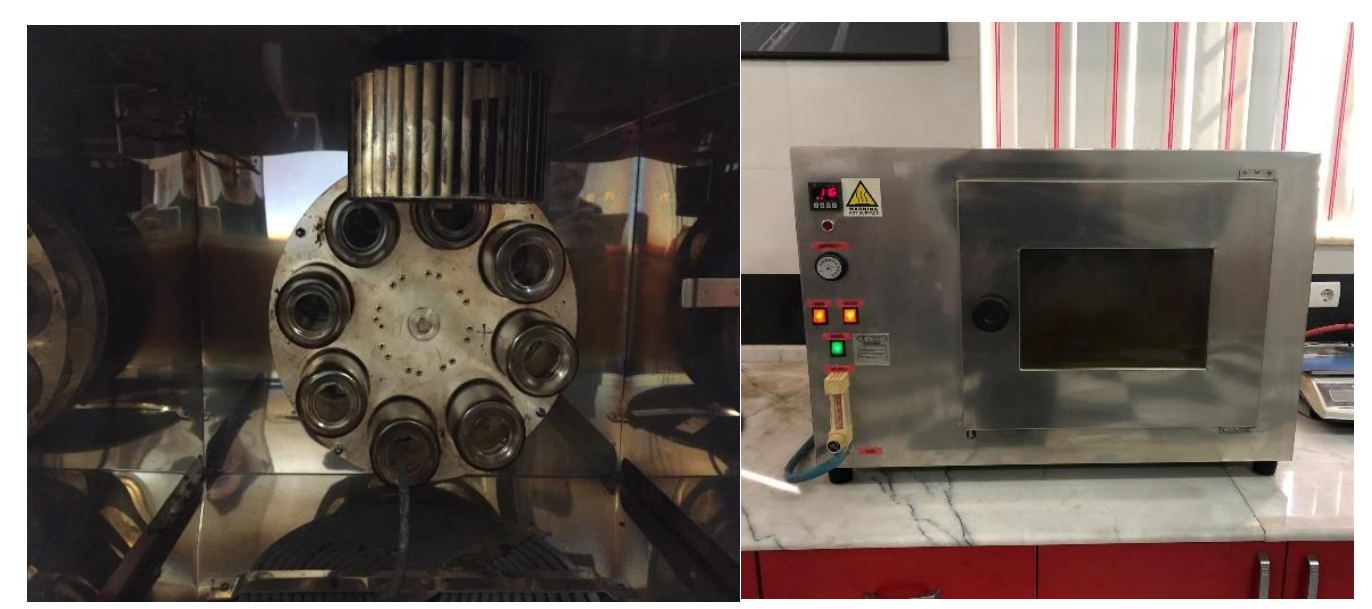

Şekil 2. RTFO cihazının iç ve dış görünümü

RTFO deneyiyle kısa süreli yaşlandırma işlemleri tamamlandıktan sonra asfalt bağlayıcılar oda sıcaklığında soğutulduktan uzun süreli yaşlandırmanı temsil eden basınçlı yaşlandırma kabı (PAV) deneyine tabi tutulması için kapalı şekilde saklanmıştır.

\subsubsection{Bağlayıcıların Uzun Süreli Yaşlandırılması}

Kaplamada trafiğe hizmet esnasında asfalt bağlayıcılarında ilk 5-10 yıl olmak suretiyle meydana gelen yaşlanmayı temsil etmesi amacıyla basınçlı yaşlandırma kabı (PAV) deneyi geliştirilmiştir Deney ASTM D6521 şartnamesi çerçevesinde uygulanmıştır (ASTM D6521, 2013).

Asfalt bağlayıcının uzun süreli yaşlanmasını hızlandırmak için RTFOT ile kısa süreli yaşlandırılmış bağlayıcıları yüksek sıcaklık performans sınıflarına göre $100^{\circ} \mathrm{C}$ sıcaklıkta 20 saat boyunca 2.1 $\pm 0.1 \mathrm{MPa}$ hava basıncı ile PAV deneyi gerçekleştirilmektedir. PAV cihazının görünümü şekil 3'te sunulmuş̧tur. 


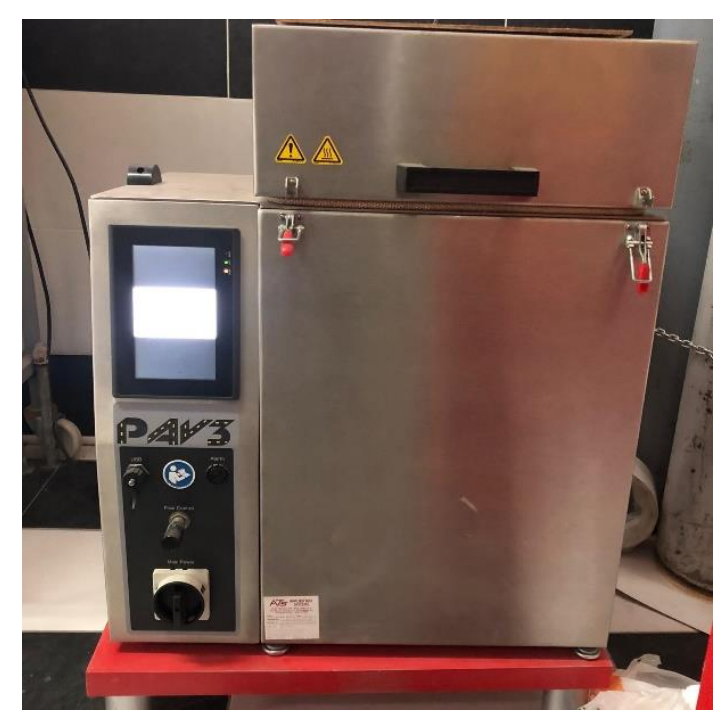

Şekil 3. PAV cihazının görünümü.

$\mathrm{Bu}$ işlemin ardından bağlayıcılar PAV asfalt bağlayıcılar yüksek hava basıncına maruz kaldığı için malzemede hava kabarcıkları oluşmaktadır. Bu kabarcıkların ortadan kaldırılmaları için degas (gaz alma) cihazı kullanılmıştır. Bu süreçte numuneler $163^{\circ} \mathrm{C}$ 'de 30 dakika degas etüvünde tutularak içerisinde sıkışan hava kabarcıklarının uzaklaştırılması sağlanmıştır.

\subsection{Yöntem}

\subsubsection{Superpave Yorulma Parametresi}

Superpave yorulma parametresi $\left(G^{*} \times \sin \delta\right)$ asfalt bağlayıcının kaplamadaki orta sıcaklık performansını temsil etmektedir. Bu parametre dinamik kayma reometresi (DSR) deneyi yardımıyla AASHTO T 315 şartnamesine uygun olarak ve uzun süreli yaşlandırılmış (RTFO+PAV) asfalt bağlayıcılardan elde edilmektedir (AASHTO T315, 2012). Çalışmada kullanılan DSR cihazının görünümü Şekil 4'te verilmiştir. DSR deneyi $12 \mathrm{rad} / \mathrm{s}$ frekansında $\% 1$ deformasyon uygulanarak orta sıcaklıklarda $\left(19-34^{\circ} \mathrm{C}\right)$ asfalt bağlayıcının yorulma çatlağına karşı direnci ölçülmüştür. Orta sıcaklık performansının değerlendirilmesinde DSR cihazına $8 \mathrm{~mm}$ çapında ve $2 \mathrm{~mm}$ kalınlığında başlık takılarak hazırlanmış numuneler üzerinde deney uygulanmıştır. 


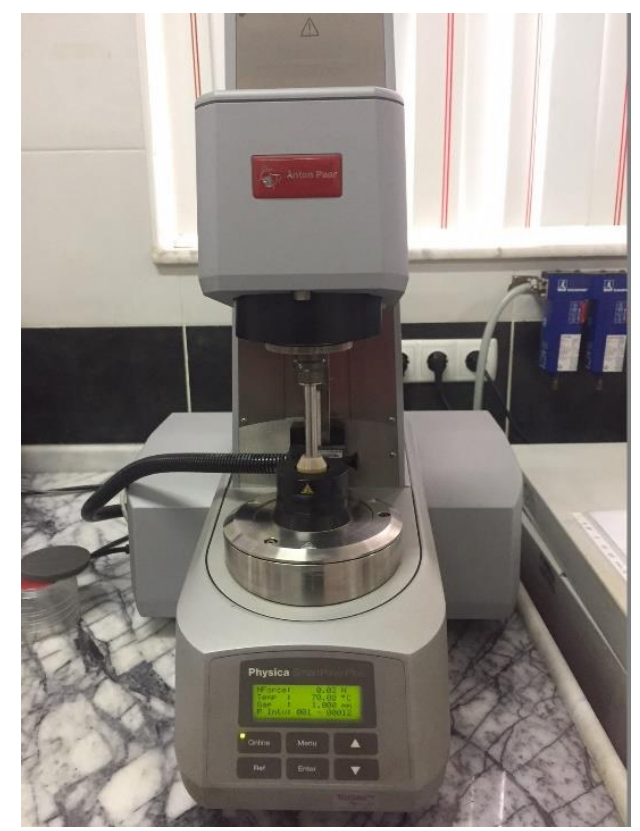

Şekil 4. Anton Paar Smart Pave Plus 301 DSR cihazı

Deneyin sonucunda kompleks kayma modülü $\left(G^{*}\right)$ ve faz açısı $(\delta)$ parametreleri elde edilmektedir. $\mathrm{Bu}$ parametreler Superpave yorulma parametresini $\left(G^{*} \times_{\sin } \delta\right)$ oluşturmaktadır. Standarda göre asfalt bağlayıcının kullanılacağı sıcaklıkta $G^{*} \times \sin \delta$ parametresinin en üst sınırı $5000 \mathrm{kPa}$ olmalıdır. Böylece, en düşük yorulma parametresi değeri asfalt bağlayıcının orta sıcaklıklarda oluşan yorulma çatlaklarına karşı daha yüksek performans sergilediği anlamına gelmektir.

\subsubsection{Lineer Farklı Genlik (LAS)}

Asfalt bağlayıcının orta sıcaklıklardaki yorulma hasarı ve yorulma ömrünü belirlemek amacıyla lineer farklı genlik (LAS) deneyi hızlandırılmış bir yöntem kapsamında gerçekleştirilmektedir (Bahia ve ark., 2013). LAS deneyi, Superpave yorulma parametresinde de olduğu gibi DSR cihazı yardımıyla $8 \mathrm{~mm}$ çapında ve $2 \mathrm{~mm}$ kalınlığındaki bağlayıcı numuneleri üzerinde $25^{\circ} \mathrm{C}$ sicaklıkta uygulanmaktadır. Asfalt kaplaması hizmet ömrü boyunca trafik yüklemesine maruz kaldığından dolayı yorulma ömrünün belirlenmesi uzun süreli yaşlandırılmış (RTFO+PAV) asfalt bağlayıcı numuneleri üzerinde incelenmektedir.

AASHTO TP101 şartnamesine göre, Denklem (1)'de verilen yorulma kanunu formulü asfalt bağlayıcının yorulma ömrünü belirlemek için VECD (viscoelastik continuum damage) teorisini kullanarak hesaplanmaktadır (AASHTO TP101, 2014). VECD teorisi, tekrarlı yüklemelere ve 
gerilmelere maruz kalan asfalt bağlayıcının yorulma hasarını ölçmek için geliştirilmiştir. Bu teorinin yardımıyla, farklı deformasyon (yükleme) seviyelerine maruz kalarak asfalt bağlayıcıların yorulma performansının öngörülmesi mümkün olmaktadır.

$$
N_{f}=A \times\left(\gamma_{p}\right)^{-B}
$$

Burada $N_{f}$, yorulma ömrü veya yorulma bozulmasına uğrayan döngü (trafik) sayısı; $\gamma_{p}$, uygulanan deformasyon genliği; $A$ ve $B$ parametreleri ise VECD teorisinin katsayılarıdır.

$A$ parametresi asfalt bağlayıcının bütünlüğünü koruma özelliğini tanımlamaktadır. Yorulma denkleminde, $\gamma_{p}$ parametresinin değeri 1 olduğunda $A$ parametresinin yorulma ömrüne (Nf) eşit olduğunu göstermektedir.

$B$ parametresi ise asfalt bağlayıcının deformasyon seviyesi değişimine karşı duyarlılığını temsil etmektedir. $B$ parametresinin mutlak değeri, yorulma ömrünü azaltma oranının bir göstergesidir. Dolayısıyla, $A$ parametresinin değeri daha yüksek olduğu ve mutlak $B$ değeri daha düşük olduğu asfalt bağlayıcının daha yüksek yorulma direncine sahip olacağı ve dolayısıyla yorulma ömrünün daha yüksek olması anlamına gelmektedir (Hassanpour-Kasanagh ve ark., 2020).

AASHTO TP101 şartnamesine göre, LAS deneyi farklı frekans ve farklı genlik deneyleri olarak iki ayrı aşamadan oluşmaktadır. Bu deneylerden birincisi, bağlayıcının reolojik özelliklerini belirlemek için uygulanırken, ikincisi bağlayıcıda oluşan hasarın ölçülmesi için kullanılmaktadır. Farklı frekans deneyinde, sabit bir deformasyonda (\% 0,1) ve 0,1-30 Hz olmak üzere geniş bir frekans aralığında yapılmaktadır. Farklı genlik deneyi ise, sabit frekansta (10 Hz) sıfırdan \%30'a kadar salınımlı doğrusal artışlı deformasyon uygulanmaktadır. Farklı genlik deneyi yaklaşık 5 dakika içinde ve 310 döngü gerçekleşmektedir.

Asfalt bağlayıcının yorulma ömrünü belirlemek için, ilk önce hasarsız malzeme özelliği $(\alpha)$ parametresi farklı frekans deneyi verileri yardımıyla hesaplanır. Bu amaçla, açısal frekansa bağlı faz açısı $\delta(\omega)$ ve kompleks kayma modülü $\left|G^{*}\right|(\omega)$ Denklem (2) suretiyle depolama modülüne $G^{\prime}(\omega)$ dönüştürülebilir.

$$
G^{\prime}(\omega)=\left|G^{*}\right|(\omega) \times \cos \delta(\omega) \mid
$$

Log-log ölçeğinde, depolama modülünün $G^{\prime}(\omega)$ açısal frekansa $(\omega)$ karşı eğimi Denklem (3)’te verilmiştir. 
$\log G^{\prime}(\omega)=m(\log \omega)+b$

Ayrıca, $\alpha$ parametresinin değeri Denklem (4)’teki dönüşüm gerçekleştirilerek hesaplanabilir.

$\alpha=\frac{1}{m}$

Zamana bağlı hasar birikimi Denklem (5) yardımıyla elde edilebilir.

$$
\mathrm{D}(\mathrm{t}) \cong \sum_{i=1}^{N}\left[\pi \gamma_{p, i}^{2}\left(C_{i-1}-C_{i}\right)\right]^{\frac{\alpha}{1+\alpha}}\left(t_{i}-t_{i-1}\right)^{\frac{1}{1+\alpha}}
$$

Burada $C(t)=\frac{\left|G^{*}\right|(t)}{\left|G^{*}\right|_{\text {initial }}} ;\left|G^{*}\right|$, kompleks kayma modülü; $\gamma_{p, i}$, belirli bir veri noktası için uygulanan kayma deformasyonu genliği, ve $t$ deney zamanı olarak tanımlanmaktadır.

Malzeme bütünlüğü $(C(t))$ ve hasar yoğunluğu $(D(t))$ arasındaki ilişki, Denklem (6) suretiyle kuvvet kanunu modeli kullanılarak açıklanmıştır.

$$
C(t)=C_{0}-C_{a} D(t)^{C_{2}}
$$

Burada $C_{0}, C^{\prime}$ nin başlangıç değeridir ve bire eşittir; $C_{1}$ ve $C_{2}$, eğri uydurma katsayılarıdır.

Yorulma noktasındaki hasar yoğunluğu $\left(D_{f}\right)$, maksimum kayma deformasyonundaki malzeme bütünlügünü $\left(C_{f}\right)$ kullanarak Denklem (7) yardımıyla hesaplanmaktadır.

$$
\mathrm{D}_{\mathrm{f}}=\left(\frac{C_{0}-C_{f}}{C_{1}}\right)^{1 / C_{2}}
$$

Son olarak, bitümün yorulma performansının değerlendirilmesinde önemli rol oynayan $A$ parametresi Denklem (8) ve $B$ parametresi Denklem (9) gibi ifade edilebilir:

$$
A=\frac{f \cdot D_{f}^{1+\alpha\left(1-C_{2}\right)}}{\left[1+\alpha\left(1-C_{2}\right)\right]\left(\pi \cdot C_{1} \cdot C_{2}\right)^{\alpha}}
$$




$$
B=2 \alpha
$$

$A, B$ ve $N_{f}$ değerleri VECD teorisinin yardımıyla her asfalt bağlayıcı numune için ayrı ayrı elde edildikten sonra bağlayııı numuneleri üzerinde oluşan yorulma hasarı ve yorulma ömrü belirlenmektedir.

\section{Bulgular ve Tartışma}

\subsection{Superpave Yorulma Parametresi}

Deneyin sonucunda asfalt bağlayıcının yorulma çatlağına karşı direnci temsil eden $\mathrm{G}^{*} \times \sin \delta$ parametresinin orta sıcaklıklardaki performansı Şekil 5'te sunulmuştur. Şartnamede yer alan katkıların yüksek sıcaklık performans PG sınıflarının orta sıcaklıkta yapılması ifadesine uygun olarak " $22^{\circ} \mathrm{C}$ " deney değerlendirme sıcaklığı olarak esas alınmıştır. EVA katkılı asfalt bağlayıcıların yorulma çatlağına karşı dirençleri sıcaklığın düşmesiyle birlikte $22^{\circ} \mathrm{C}$ 'a ulaşana kadar sürekli azalmakta ve böylelikle maksimum 5000 kP Superpave standart kriteri sağladığ1 görülmektedir. Buna göre, tüm farklı katkı oranlarına sahip EVA katkılı bağlayıcılar $22^{\circ} \mathrm{C}^{\prime} \mathrm{de} 5000$ kP üst sınırını aşmamıştır. Bunun yanı sıra, EVA katkısının saf bağlayıcıya eklenme seviyesi arttıkça $\mathrm{G}^{*} \times \sin \delta$ parametresi değerinde düşüş gözlemlenmiştir. Bu sonuç, EVA katkısının bağlayıcının sertliğini arttırmasına rağmen kırılgan hale dönüşmesini önleyerek aynı zamanda bağlayıcıya elastikiyet kazandırdığı ifade etmekte ve sonuç olarak orta sıcaklıklarda yorulma çatlağına karşı dirençli olduğunu ortaya çıkarmaktadır.

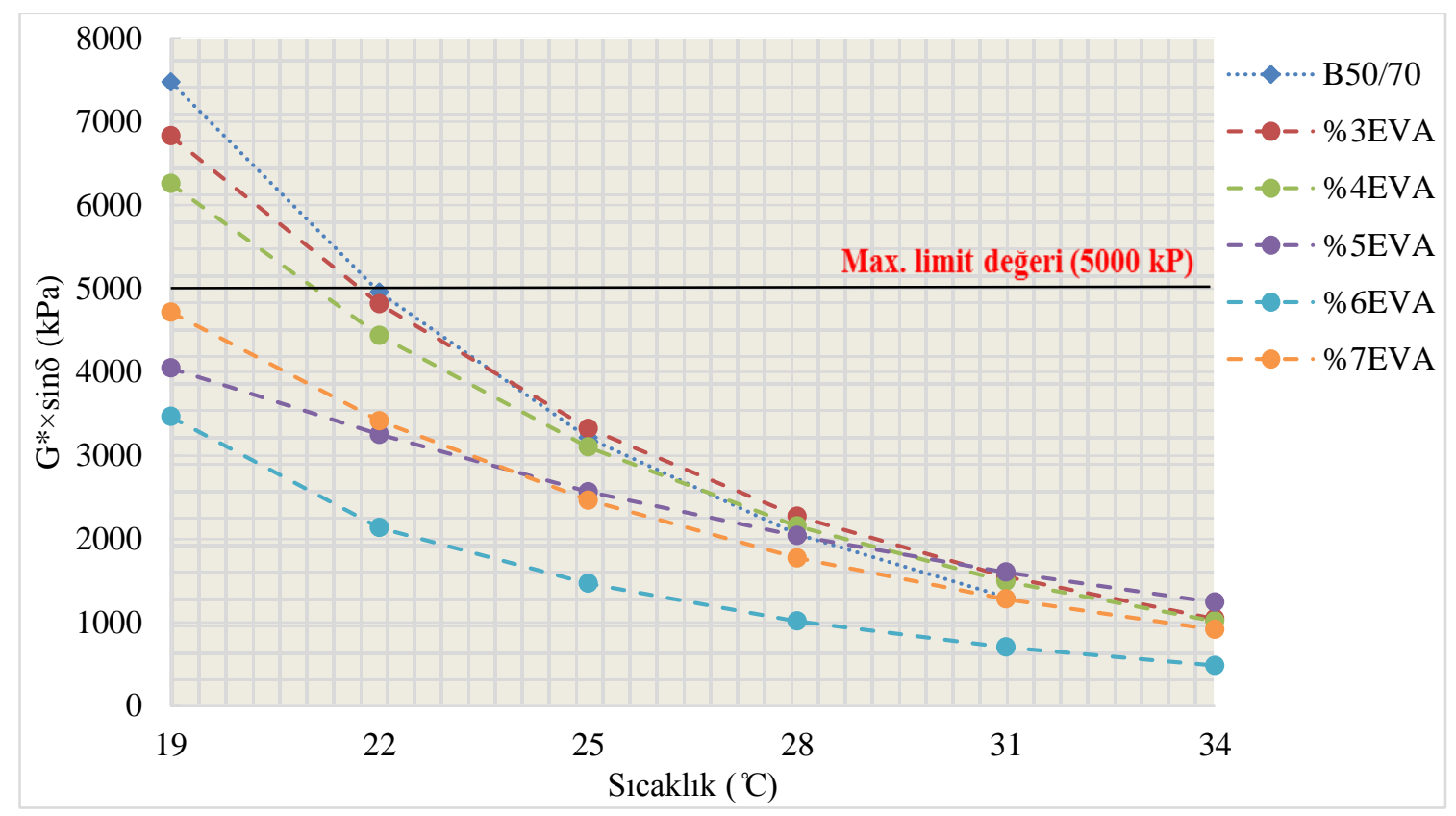

Şekil 5. Superpave yorulma parametresi 


\subsection{VECD Teorisiyle Yorulma Ömrü Tahmini}

Çalışmada, EVA katkılı asfalt bağlayıcılar lineer farklı genlik (LAS) deneyine tabi tutulmuştur. Deney sonuçların analizi VECD teorisi yardımıyla gerçekleştirilerek yorulma hasarı ve ömrü tahmini Şekil 6-10’da sunulmuştur.

Şekil 6'da görüldüğü gibi, tüm bağlayıcıların bütünlüğü $(C)$ düştükçe malzemedeki yorulmadan kaynaklanan hasar yoğunluğu $(D)$ artmaktadır. EVA katkı seviyesi arttıkça, sabit bir hasar yoğunluğu noktasında malzeme bütünlüğü saf bağlayıcıya göre belirgin şekilde iyileşmiştir. $\mathrm{Bu}$, EVA katkılı bağlayıcının asfalt kaplamadaki hizmet sırasında oluşacak yorulma hasarını azaltabileceğini göstermektedir.

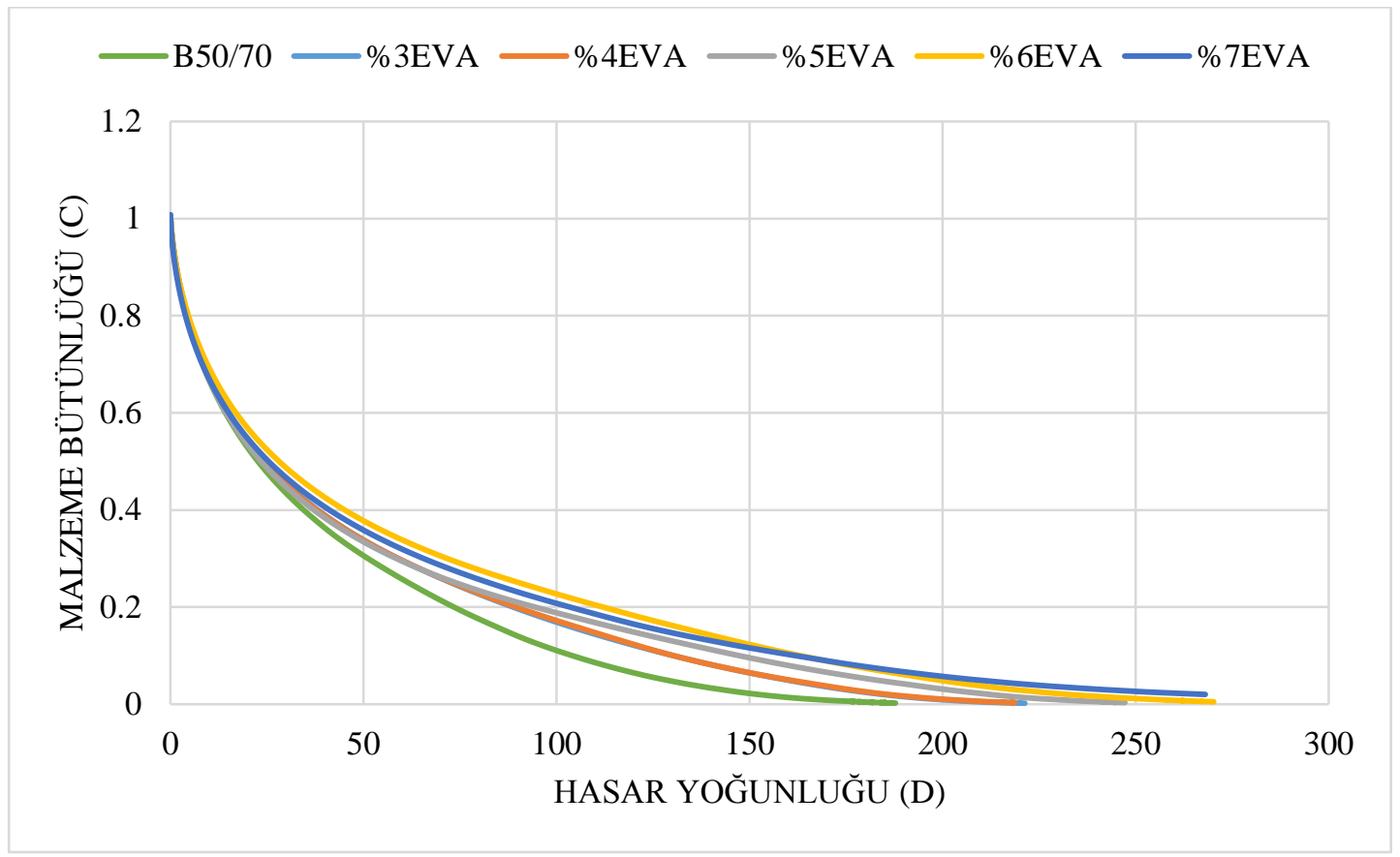

Şekil 6. VECD teorisi üzerinde malzeme bütünlüğü (C) ve hasar yoğunluğu (D)

EVA katkılı asfalt bağlayıcıların kendi bütünlüğünü koruma özelliği ( $A$ parametresi) ve deformasyon seviyesi değişimine karşı duyarlılığg (B parametresi) sıra ile Şekil 7 ve Şekil 8'de sunulmuştur.

EVA katkısının asfalt bağlayıcıya eklenmesi $A$ parametresi ve $B$ parametresinin mutlak değerini arttırmış ve dolayısıyla Denklem (1)'de yer alan yorulma ömründe $\left(N_{f}\right)$ artış sağlamıştır. Örneğin, bağlayıcının $A$ parametresinin değeri 9.21E+04 iken en düşük modifikasyon seviyesinde (\%3) bu değer 6.88E+05 olmuştur. Böylece bağlayıcının bütünlüğünü koruma özelliğinde 7,47 kat 
artış sağlamıştır. Bununla birlikte, en yüksek modifikasyon seviyesinde (\%7) ise 4.70E+06'ya yükselerek saf asfalt bağlayıcıya göre 51 kat artış göstermiştir (Şekil 7).

Şekil 8'de $B$ parametresi incelendiğinde, en düşük modifikasyon seviyesinde (\%3) bağlayıcının B parametresinin mutlak değerinin 3,043'ten 3,888'e yükseldiği görülmektedir. Bu sonuç deformasyon seviyesi değişimine karşı duyarlılığının 1,28 kat arttığı anlamına gelmektedir. En yüksek modifikasyon seviyesinde (\%7) ise, “ $B$ ” değeri 4,587 olarak hesaplanmış, böylelikle saf bağlayıcıya göre 1,18 kat artışın sağlandığı tespit edilmiştir. $B$ parametresinin artışı bitümün yorulma ömrünün azalmasına neden olmaktadır. $\mathrm{Bu}$ sonuç itibariyle, $B$ parametresinin mutlak değeri ne kadar düşük olursa bitümün deformasyon (yükleme) seviyesi değişimine duyarlılığı o kadar az olmakta ve bunların neticesinde yorulma ömrü artmaktadır.

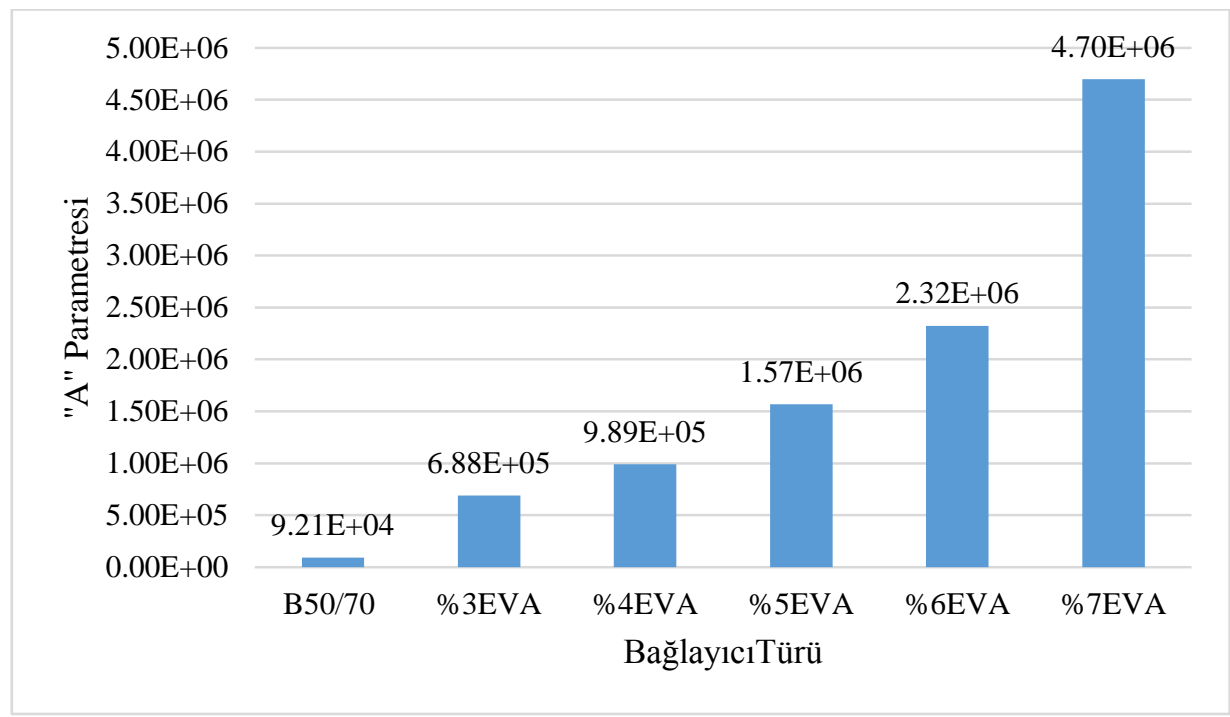

Şekil 7. Malzeme bütünlüğünü koruma özelliği (A parametresi)

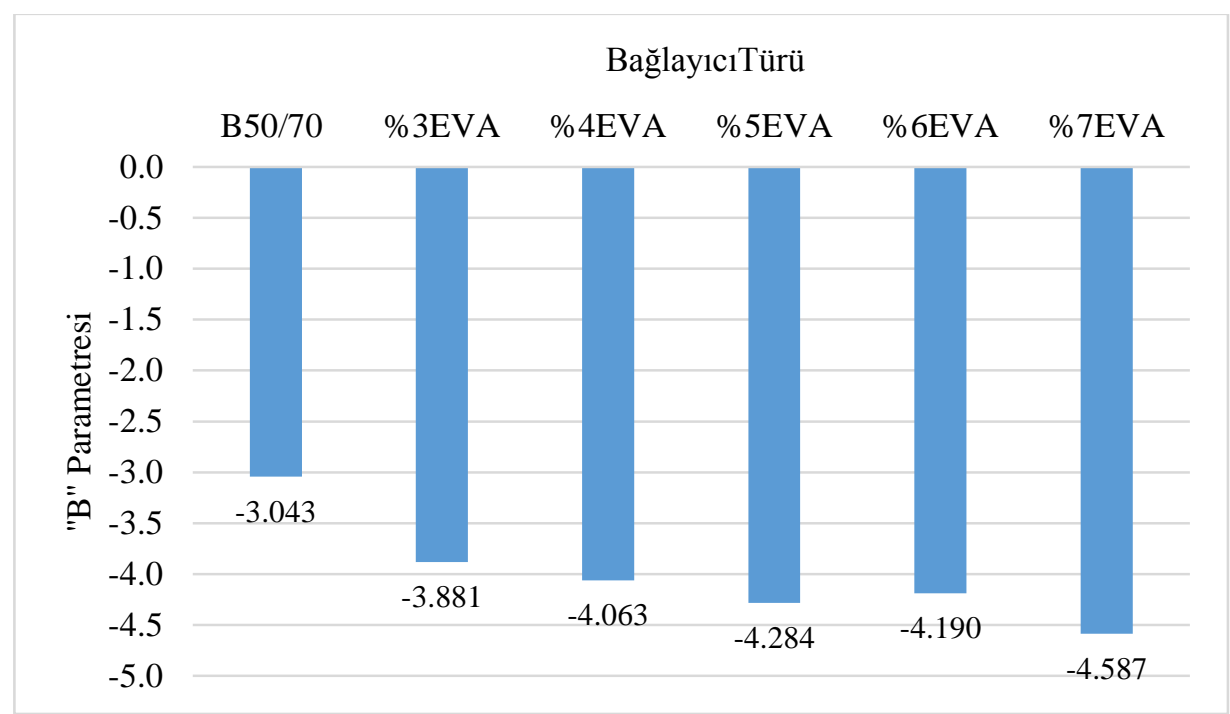

Şekil 8. Deformasyon seviyesi değişimine karşı duyarlılık ( $B$ parametresi) 
$A$ ve $B$ parametrelerin sonuçlarını kullanarak yüzde 0 ila 30 arası doğrusal artışlı deformasyonlara maruz kalan bağlayıcıların yorulma ömrü değişimi yorulma kanunu $\left(N_{f}=A \times \gamma^{-B}\right)$ yardımıyla hesaplanarak Şekil 9' da görsel olarak sunulmuştur. Sonuçlar, EVA katkılı bağlayıcıların bitümün yorulma ömrünü düşük deformasyon seviyelerinde arttırdığı belirgin bir şekilde ortaya koymaktadır. Öte yandan, EVA polimer katkısı yüksek deformasyon düzeyinde (\%10-30) bağlayıcının yorulma ömrünü olumsuz yönde etkilemiştir. Buna ek olarak, EVA katkılı bağlayıcıların yorulma ömrünün deformasyon düzeyine bağlı olarak değişkenlik gösterdiği ortaya konmuştur. Ancak, BSK'ların içerisinde bağlayıcı olarak rol alan bitümün arazide hizmet esnasında daha düşük trafik yüklerine maruz kaldığı (yaklaşık \%1-5 deformasyon) bilinmektedir (Masad ve ark., 2001). Dolayısıyla, EVA katkısının bağlayıcının yüksek deformasyondaki yorulma ömrüne olan bu olumsuz etkisinin önem derecesinin düşük deformasyon seviyelerindeki yorulma ömrüne göre daha az olduğu düşünülmektedir.

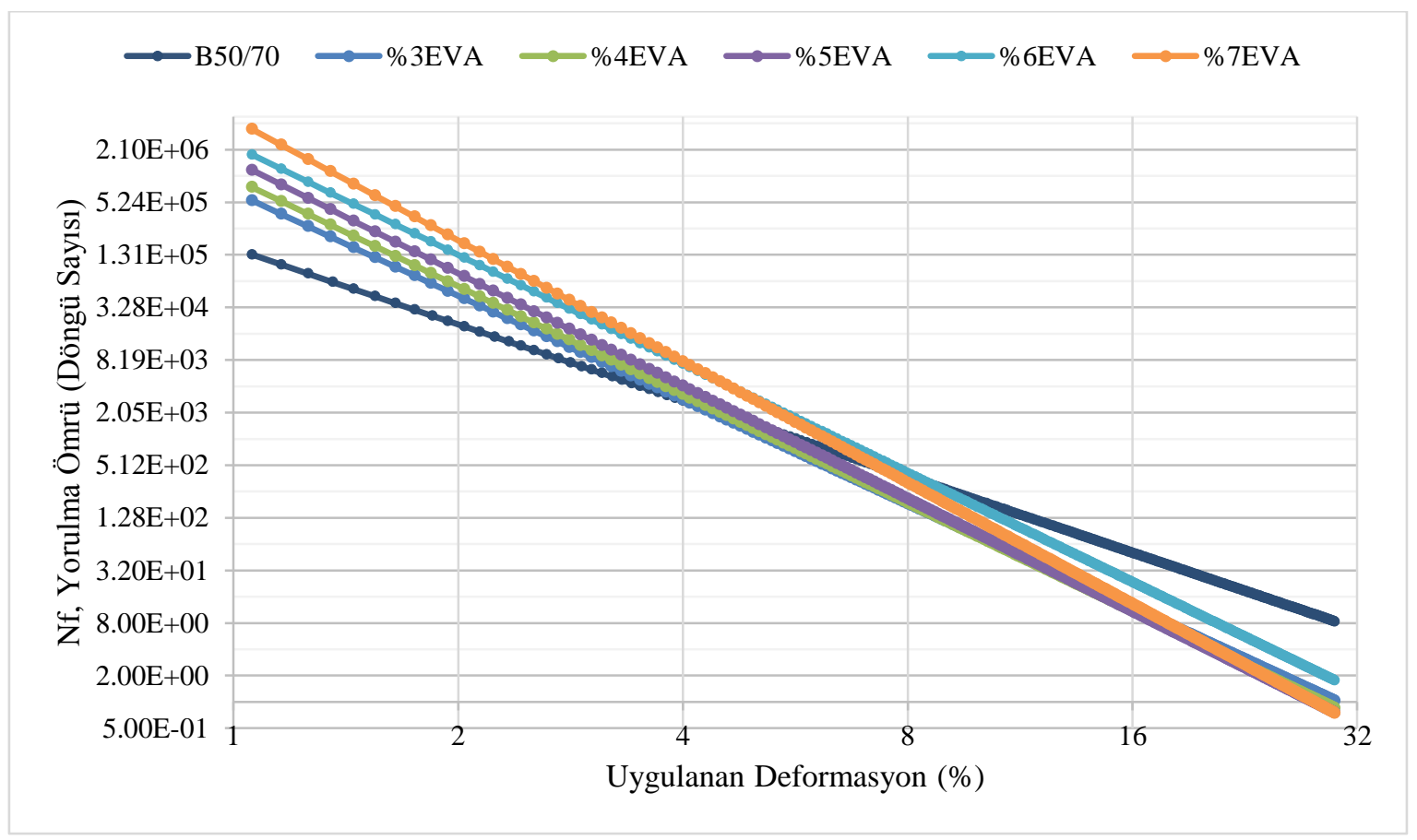

Şekil 9. Geniş deformasyon seviyesi üzerinde yorulma ömrü

VECD teorisine ait hesaplamalar sonucunda elde edilen parametreler iki farklı deformasyon seviyesinde (\%2,5 ve \%5) yorulma denklemlerine yerleştirilerek iki farklı $N_{f}$ değerleri elde edilmektedir. Deformasyonun iki farklı düzeyde hesaplanmasının nedeni asfalt kaplamasında tasarlanan kaplama tabakası kalınlığıdır. Deformasyon miktarı kalın tabakalar (tabaka kalınlığı >4 inç) için \%2,5 ve ince tabakalar (tabaka kalınlığı <4 inç) için \%5 olarak dikkate alınmaktadır 
(Masad ve ark., 2001). Bu değerlendirmeler sonucunda, EVA katkılı bağlayıcıların iki farklı deformasyondaki yorulma ömrü $\left(N_{f}\right)$ Şekil 10'da verilmiştir. Görüldüğü üzere, saf bağlayıcının $N_{f}$ değeri \%2,5 deformasyonda 5669 döngüde, \%3 EVA katkılı bağlayıcısı ise 18116 döngü sonunda (trafik sayısı) yorulma bozulmasına uğramıştır. Döngüler oranlandığında 3,20 kat mertebesinde bir artışın EVA katkısı sonrasında sağlandığı anlaşılmaktadır.

Döngü sayısının \%7 EVA katkılı bağlayıcısı için 68081 (trafik sayısı) olarak belirlendiği ve bu değerin saf bağlayıcıya oranla 12 kat fazla olduğu tespit edilmiştir. EVA katkılı bağlayıcıların yorulma ömrü \%2,5 deformasyonda belirgin bir artış sağlamasına rağmen $\% 5$ deformasyonda artış olsa bile göze çarpan bir değişiklik görülmemiştir. Bu sayede, EVA katkısının bağlayıcılara eklenmesinin artışı ile kalın tabakaya ait yorulma ömrünün artış eğilimi ince tabakada meydana gelen artış eğiliminden daha fazla olmuştur.

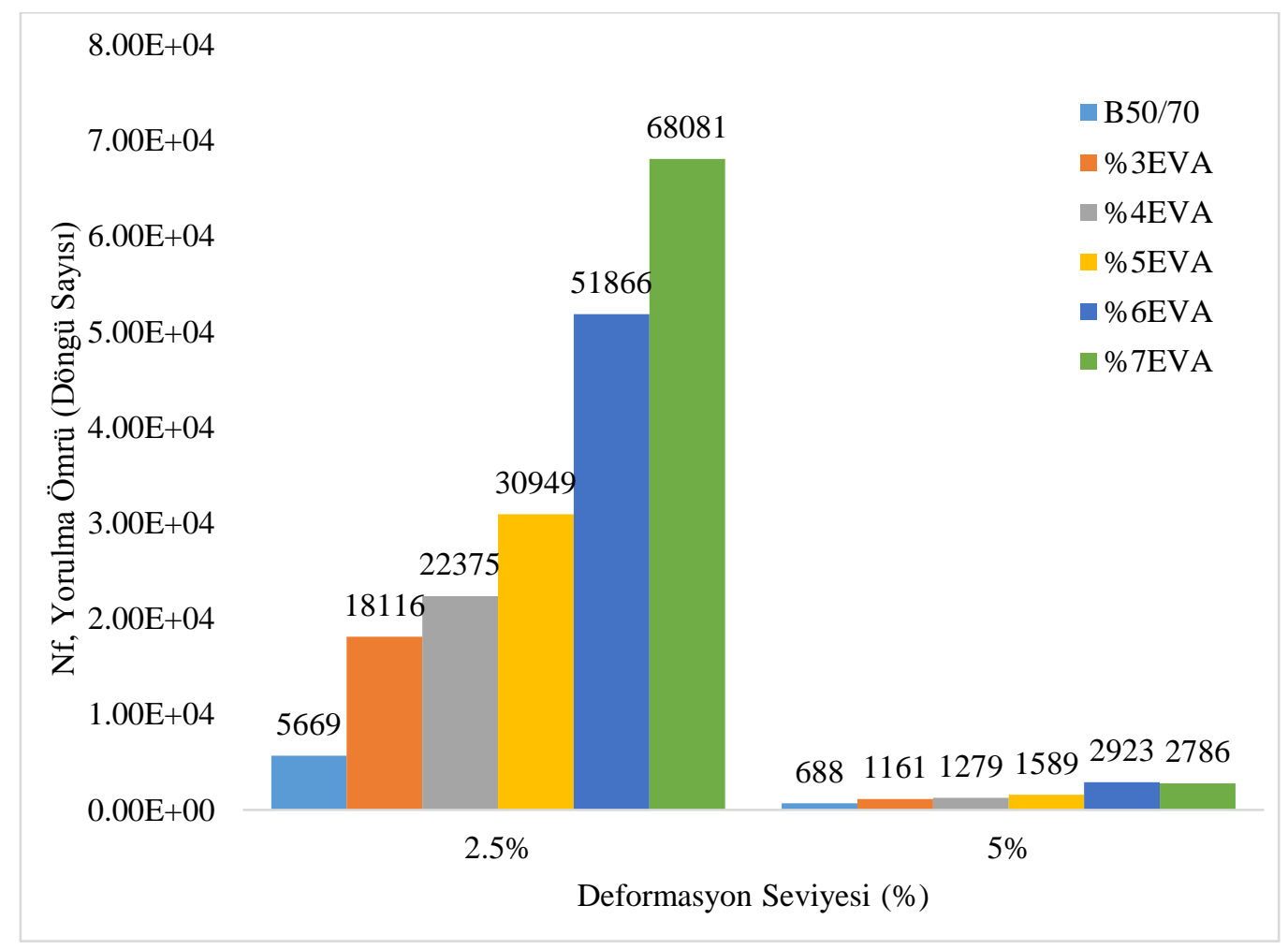

Şekil 10. \%2.5 ve \%5 deformasyon seviyesine göre yorulma ömrü 


\section{Sonuçlar ve Öneriler}

$\mathrm{Bu}$ çalışmada, uzun süreli yaşlandırılmış EVA polimer katkılı 50/70 penetrasyon sınıfına sahip bitümün asfalt kaplamadaki yorulma çatlaklarına karşı direnci, yorulma hasarı ve yorulma ömrü tahmini gerçekleştirilmiştir ve elde edilen sonuçlar aşağıda verilmiştir.

- Tüm EVA katkılı bağlayıcılar orta sıcaklık bölgesi için belirlenen $22^{\circ} \mathrm{C}^{\prime}$ ye kadar $5000 \mathrm{kP}$ üst sınırını sağlamışlardır. EVA katkısı saf bitümün sertliğini arttırmasına rağmen kırılgan hale dönüşmesini önleyerek aynı zamanda elastikiyet kazandırmış ve böylece bitümde $22^{\circ} \mathrm{C}$ 'ye kadar yorulma çatlağı oluşmasını önlemiştir.

- VECD teorisinin değerlendirmelerinde, EVA katkılı bağlayıcılar saf bitümün bütünlüğünü koruma özelliğini arttırarak ve deformasyon seviyesi değişimine karşı duyarlılığını düşürerek yorulma bozulmasına meydana getirecek döngü (trafik) sayısını belirgin biçimde arttırdığı tespit edilmiştir.

- EVA katkısı saf bitümün kendi bütünlügüüü arttırarak asfalt kaplamadaki hizmet sırasında oluşacak yorulma hasarını azalttığı belirlenmiştir. Bunun yanı sıra, asfalt kaplamalarda bitümün maruz kalacağı deformasyon seviyelerinde kaplamanın daha az yorulma hasarına uğramasıyla yorulma ömrü $\left(N_{f}\right)$ değerinin uzayacağı tespit edilmiştir.

- Katkı işlemi sonrasında hem yorulma bozulması meydana getirecek trafik sayısındaki artış hem de \%2,5 deformasyon seviyesindeki yorulma açısından meydana gelen performans artışı, çalışmada kullanılan EVA polimer katkılı bağlayıcıların esnek üstyapılarda yorulma ömrü açısından kullanımının uygun olduğunu ortaya koymaktadır.

- EVA katkılı bağlayıcıların BSK'lar içerisinde optimüm miktarı bulunarak karışım esaslı deneyler gerçekleştirilerek yorulma performansının belirlenmesi ve bu sayede bağlayıcı ve karışımın yorulma performansının karşılaştırılması önerilmektedir.

\section{Yazarların Katkısı}

Çalışmada bütün yazarlar eşit oranda katkı sunmuştur.

\section{Çıkar Çatışması Beyanı}

Yazarlar arasında herhangi bir çıkar çatışması bulunmamaktadır.

\section{Araştırma ve Yayın Etiği Beyanı}

Yapılan çalışmada, araştırma ve yayın etiğine uyulmuştur. 


\section{Kaynaklar}

AASHTO T315. (2012). Standard method of test for determining the rheological properties of asphalt binder using a dynamic shear rheometer (DSR). In American Association of state and highway transportation officials (p. 33). Washington, DC.

AASHTO TP101. (2014). Estimating Damage Tolerance of Asphalt Binders Using the Linear Amplitude Sweep. In American Association of state and highway transportation officials.

Ameri, M., Mansourkhaki, A., and Daryaee, D. (2018). Evaluation of fatigue behavior of high reclaimed asphalt binder mixes modified with rejuvenator and softer bitumen. Construction and Building Materials, 191, 702-712. https://doi.org/10.1016/j.conbuildmat.2015.01.008

Ashish, P. K., Singh, D., and Bohm, S. (2017). Investigation on influence of nanoclay addition on rheological performance of asphalt binder. Road Materials and Pavement Design, 18(5), 1007-1026. https://doi.org/10.1080/14680629.2016.1201522

ASTM D2872. (2012). Standard test method for effect of heat and air on a moving film of asphalt (rolling thin-film oven test). In USA: Annual Book of ASTM Standards.

ASTM D6521. (2013). Standard practice for accelerated aging of asphalt binder using a pressurized aging vessel (PAV). In USA: Annual Book of ASTM Standards.

Bahia, H., Tabatabaee, H. A., Mandal, T., and Faheem, A. (2013). Field evaluation of Wisconsin modified binder selection guidelines-Phase II. Wisconsin Highway Research Program.

Behnood, A., and Gharehveran, M. M. (2019). Morphology, rheology and physical properties of polymermodified asphalt binders. European Polymer Journal, 112, 766-791. https://doi.org/10.1016/j.eurpolymj.2018.10.049

Hassanpour-Kasanagh, S., Ahmedzade, P., Fainleib, A. M., and Behnood, A. (2020). Rheological properties of asphalt binders modified with recycled materials: A comparison with Styrene-Butadiene-Styrene $\begin{array}{lllll}\text { (SBS). } \quad \text { Construction and } & \text { Building }\end{array}$ https://doi.org/10.1016/j.conbuildmat.2019.117047

Kalantar, Z. N., Karim, M. R., and Mahrez, A. (2012). A review of using waste and virgin polymer in pavement. Construction and Building Materials, 33, 55-62. https://doi.org/10.1016/j.conbuildmat.2012.01.009

Kataware, A. V, and Singh, D. (2018). Evaluation of intermediate temperature cracking performance of warm mix additive modified asphalt binders. Construction and Building Materials, 184, 165-176. https://doi.org/10.1016/j.conbuildmat.2018.06.227

Masad, E., Somadevan, N., Bahia, H. U., and Kose, S. (2001). Modeling and experimental measurements of strain distribution in asphalt mixes. Journal of Transportation Engineering, 127(6), 477-485. https://doi.org/10.1061/(ASCE)0733-947X(2001)127:6(477)

Nasr, D., and Pakshir, A. H. (2019). Rheology and storage stability of modified binders with waste polymers 
Uzun Süreli Yaşlandırılmış Etilen Vinil Asetat (EVA) Polimer Katkll Asfalt Bağlayıcının Yorulma Ömrünün Incelenmesi

composites. Road Materials and Pavement Design, 20(4), 773-792. https://doi.org/10.1080/14680629.2017.1417152

Saboo, N., and Kumar, P. (2015). A study on creep and recovery behavior of asphalt binders. Construction and Building Materials, 96, 632-640. https://doi.org/10.1016/j.conbuildmat.2015.08.078

Sabouri, M., Mirzaiyan, D., and Moniri, A. (2018). Effectiveness of Linear Amplitude Sweep (LAS) asphalt binder test in predicting asphalt mixtures fatigue performance. Construction and Building Materials, 171, 281-290. https://doi.org/10.1016/j.conbuildmat.2018.03.146

Sadeghian, M., Namin, M. L., and Goli, H. (2019). Evaluation of the fatigue failure and recovery of SMA mixtures with cellulose fiber and with SBS modifier. Construction and Building Materials, 226, 818826. https://doi.org/10.1016/j.conbuildmat.2019.07.308

Sengoz, B., and Isikyakar, G. (2008). Evaluation of the properties and microstructure of SBS and EVA polymer modified bitumen. Construction and Building Materials, 22(9), 1897-1905. https://doi.org/10.1016/j.conbuildmat.2007.07.013

Ziari, H., Babagoli, R., Ameri, M., and Akbari, A. (2014). Evaluation of fatigue behavior of hot mix asphalt mixtures prepared by bentonite modified bitumen. Construction and Building Materials, 68, 685-691. https://doi.org/10.1016/j.conbuildmat.2014.06.066 